\title{
Prevalence of obstructive sleep apnea among patients with chronic obstructive pulmonary disease
}

\author{
Osama Ibrahim Mohammad, Ahmed Gouda Elgazzar, Shymaa Mohammad Mahfouz and \\ Marwa Elsayed Elnaggar* (1)
}

\begin{abstract}
Background: The conjunction of chronic obstructive pulmonary disease (COPD) and obstructive sleep apnea (OSA) is known as overlap syndrome (OS). The coexistence of these diseases has cardiovascular morbidity and mortality. The aim of this study is to assess the prevalence of OSA in COPD patients. One hundred COPD patients (obese and nonobese) performed sleep questionnaires and polysomnograms.

Results: OSA prevalence in COPD was 50\% and it increases with increasing disease severity $(P<0.001)$. The highest prevalence of OSA was found in obese patients with severe COPD; $90.5 \%$ of these patients have OSA. In the OSA group, obese patients were found to have significantly higher STOP-Bang Questionnaire (SBQ), Epworth Sleep Scale (ESS), modified medical research council (mMRC) dyspnea scale, apnea-hypopnea index (AHI), respiratory disturbance index (RDI), and oxygen desaturation index (ODI). Both obese and non-obese COPD patients showed significant positive correlations between $\mathrm{AHI}$ and smoking index (SI), SBQ, ESS, mMRC, ODI, and neck circumference (NC).

Conclusions: From this study, it can be concluded that moderate and severe COPD patients had a higher diagnosis of sleep-disordered breathing. Also, obese-COPD patients are more susceptible to develop OSA.

Trial registration: Name of the registry: Benha University Protocol Record Benha U123, Obstructive Sleep Apnea Prevalence in Patients With Chronic Obstructive Pulmonary Diseases. Trial registration number:NCT04903639. Date of registry: 5/22/2021 (retrospective study).
\end{abstract}

Keywords: COPD, OSA, OS, AHI

\section{Background}

Chronic obstructive pulmonary disease (COPD) is a common, preventable, and treatable illness that is characterized by persistent respiratory symptoms and airflow limitation due to airway and additionally alveolar abnormalities ordinarily brought about by critical exposure to harmful particles or gasses [1].

Obstructive sleep apnea (OSA) is a sleep disorder that includes discontinuance or a significant reduction in airflow in the presence of breathing effort bringing about

\footnotetext{
*Correspondence: marwa_141282@hotmail.com
}

Faculty of Medicine, Benha University, Benha, Egypt nighttime hypoxemia and arousals from sleep [2]. The coexistence of COPD and OSA, known as overlap syndrome (OS), was first described by David Flenley 30 years ago, and he pointed out that a sleep study should be considered in obese COPD patients, in the individuals who snore, or those who complain of headache following nocturnal oxygen therapy to detect the presence of associated OSA [3]. The Global Burden Disease Study predicted that COPD which was known as the sixth driving reason of death in 1990 will turn out to be the third universal driving reason of death in 2020. A more up-todate prediction assessed that COPD will be the fourth driving mortality reason by 2030 [4] Patients with COPD 
and OSA have a serious possibility of morbidity and mortality in comparison with those with either disease alone. Overlap syndrome has a prevalence of $14 \%$ among patients with mild COPD and $11 \%$ among OSA patients [5]. Obviously, sleep has harmful effects on breathing, respiratory drive, and functions of the lung. While these impacts can be ignored in healthy subjects, they can lead to catastrophic consequences especially in at-risk patients with the overlap syndrome. These patients may undergo marked hypoxemia and hypercapnia, diminshed quality of life, and elevated possibilty of death [6]. In this manner, assessing the presence of OSA in patients with advanced COPD appears to be intelligent as the simultaneousness of these diseases may conceivably clarify the high cardiovascular morbidity and mortality in those patients [7].

The aim of this study was to assess the prevalence of OSA in COPD patients.

\section{Methods}

Three hundred patients were enrolled in this prospective observational study who attended at chest department, outpatient clinic, Benha University Hospitals for followup between August 2018 and October 2020. According to medical history, clinical examination, and pulmonary function tests, only stable COPD patients (100 patients) were included. The research ethics committee at the faculty of medicine has approved the study and all patients provided informed consent before participation.

COPD patients were divided according to their body mass index (BMI) into two groups [8]: group A, 50 obese COPD patients $\left(B M I \geq 30 \mathrm{~kg} / \mathrm{m}^{2}\right)$; and group $B, 50$ nonobese COPD patients $\left(\mathrm{BMI} \leq 29.9 \mathrm{~kg} / \mathrm{m}^{2}\right)$.

\section{Inclusion criteria}

COPD patients were diagnosed according to the Global Initiative for Chronic Obstructive Pulmonary Disease on the basis of GOLD, 2017. Included patients who had a chronic cough, sputum production, dyspnea, and/or a history of exposure to risk factors for the disease and confirmed by the presence of a postbronchodilator forced expiratory volume in the 1st second/forced vital capacity $(\mathrm{FEV} 1 / \mathrm{FVC})<70 \%[9]$.

\section{Exclusion criteria}

Exclusion criteria included patients with COPD exacerbation; very severe COPD patients (postbronchodilator FEV $1<30 \%$ anticipated or $<50 \%$ anticipated + chronic respiratory failure); patients with decompensated heart failure; thyroid dysfunction; ears, nose, and throat (ENT) causes of OSA; or patients with impaired hepatic and renal function.
COPD patients were characterized by their postbronchodilator FEV1 into mild (FEV1 $\geq 80 \%$ anticipated), moderate $(50 \% \leq \mathrm{FEV} 1<80 \%$ anticipated $)$, and severe $(30 \% \leq \mathrm{FEV} 1<50 \%$ anticipated $)$.

All patients included in this study were subjected to full history taking, physical examination (general including BMI and neck circumference (NC), local chest examination, oral, and ENT), questionnaires [The Epworth Sleepiness Scale (ESS) which translated to Arabic according to Anwar et al. [10], STOP-Bang Questionnaire (SBQ) [11], modified medical research council (mMRC) breathlessness scale which was translated ta Arabic according to Alyamani et al.] [12], spirometry which was done using JAEGER carefusion Germany $234 \mathrm{GmbH}$ Lelbnizstr .7, 97,204 Hoechberg, Germany. Spirometry was done during stability of the disease. Echocardiography, liver, kidney, and thyroid function tests [triiodothyronine (T3), thyroxine (T4), and thyroid-stimulating hormone (TSH)] were done (overnight polysomnography (PSG) (SOMNO Screen Plus; SOMNO Medics GmbH, Randersacker, Germany)). The polysomnography consists of electroencephalogram (EEG), electrooculogram (EOG), electrocardiogram (ECG), electromyogram (EMG), pulse oximetry, thoracic and abdominal straps, body posture sensor, nasal thermistor, and nasal cannula to assess respiratory flow and pressure and bipolar channel limb movements (tibialis anterior). Electrodes and sensors were attached to patients by sleep physiologists. Data collection was obtained following signal perception by preprocessed computer (DOMINO Software, ver. 2.6.0; SOMNO Medics GmbH).

Patients considered having apnea if they had cessation of respiration for at least $10 \mathrm{~s}$, hypopnea defined as an event that lasts for $\geq 10 \mathrm{~s}$ and is characterized by a decrease from baseline in the amplitude of breathing during sleep that either reaches $>30 \%$ with an oxygen desaturation of $4 \%$ or an arousal. The apnea-hypopnea index (AHI) is gotten from the absolute number of apneas and hypopneas separated by the total sleep time. Cutoff levels on AHI incorporate 5-15 episodes per hour for mild, 15-30 episodes per hour for moderate, and more than 30 episodes per hour for severe OSA [13].

\section{Statistical analysis [14]}

The gathered data were computerized and statistically analyzed utilizing IBM SPSS (Statistical Package for Social Science) statistic for Windows, version 24.0 Armonk, NY: IBM Corp. Qualitative data were addressed as frequencies and relative percentages. Chi-square test $\left(x^{2}\right)$ and Fisher's exact test were utilized to the figure differentiation between qualitative variables. Quantitative data were expressed as median and range for being non-parametric data (not normally distributed). 
Mann-Whitney test was utilized to detect dissimilarity between quantitative variables in two groups for nonparametric variables. Spearman's correlation test was utilized for correlating non-parametric variables. Multiple linear regression analysis was performed to show the relationship of AHI with different variables.

\section{Results}

Smoking index, BMI, and neck circumference were significantly higher in the obese group. However, there was no statistically significant difference between both groups concerning age or sex distribution. Male gender was higher in both groups (Table 1). Obese and nonobese groups differed significantly regarding Pre FEV1, Pre FVC, and post FEV1\% predicted as they were higher in non-obese groups. Also, both groups differed significantly as regard SBQ, ESS, mMRC questionnaires, AHI, respiratory disturbance index (RDI), and oxygen desaturation index (ODI) as they were statistically higher in obese patients (Table 2). OSA prevalence in COPD was $50 \%$, and it increases with increasing disease severity (Table 3). The highest prevalence of OSA was found in obese patients with severe COPD (90.5\%) (Table 4). In the OSA group, obese patients were found to have

Table 1 Comparison between the studied groups regarding clinico-demographic data

\begin{tabular}{|c|c|c|c|c|c|}
\hline \multirow[t]{3}{*}{ Parameter } & & \multicolumn{2}{|l|}{ Group } & \multirow[t]{3}{*}{ MW test } & \multirow[t]{3}{*}{$P$} \\
\hline & & $\begin{array}{l}\text { Non-obese } \\
N=50\end{array}$ & $\begin{array}{l}\text { Obese } \\
N=50\end{array}$ & & \\
\hline & & Median (range) & Median (range) & & \\
\hline \multicolumn{2}{|l|}{ Age(years) } & $64(42-75)$ & $64(46-72)$ & -0.8 & 0.409 \\
\hline \multicolumn{2}{|l|}{ SI (pack/year) } & $40(10-140)$ & $65(14-150)$ & -2.2 & $0.02^{*}$ \\
\hline \multicolumn{2}{|l|}{ BMI $\left(\mathrm{kg} / \mathrm{m}^{2}\right)$} & $26.7(20.4-28.5)$ & $43(31-64)$ & -7.5 & $<0.001^{* *}$ \\
\hline \multirow{2}{*}{\multicolumn{2}{|c|}{$\mathrm{NC}(\mathrm{cm})$}} & $32(30-36)$ & $40(38-46)$ & -2.6 & $0.01^{*}$ \\
\hline & & $N(\%)$ & $N(\%)$ & $x^{2}$ & $P$ \\
\hline \multirow[t]{2}{*}{ Sex } & Male & $40(80 \%)$ & 44 (88\%) & 0.67 & 0.41 \\
\hline & Female & $10(20 \%)$ & $6(12 \%)$ & & \\
\hline
\end{tabular}

$S /$ smoking index, $B M I$ body mass index, NC neck circumference, $M W$ Mann-Whitney test, $X^{2}$ chi-square test

*Significant

**Highly significant

Table 2 Comparison of PFTs sleep questionnaire and sleep parameter between both groups

\begin{tabular}{|c|c|c|c|c|}
\hline \multirow[t]{3}{*}{ Parameter } & \multicolumn{2}{|l|}{ Groups } & \multirow[t]{3}{*}{ MW test } & \multirow[t]{3}{*}{$\mathbf{P}$} \\
\hline & $\begin{array}{l}\text { Non-obese } \\
N=50\end{array}$ & $\begin{array}{l}\text { Obese } \\
N=50\end{array}$ & & \\
\hline & Median (range) & Median (range) & & \\
\hline PRE FEV1 (\%predicted) & $60(29-82)$ & $52(28-79)$ & -4.1 & $<0.001^{* *}$ \\
\hline PRE FVC (\%predicted) & $68(40-80)$ & $59(32-73)$ & -2.4 & $0.016^{*}$ \\
\hline Post FEV1 (\%predicted) & $68(33-84)$ & $59(31-80)$ & -3.9 & $0.00008^{* *}$ \\
\hline SBQ & $3(2-5)$ & $4(3-7)$ & -2.8 & $0.005^{*}$ \\
\hline ESS & $18(11-24)$ & $22(11-24)$ & -2.7 & $0.007^{*}$ \\
\hline $\mathrm{mMRC}$ & $2(2-3)$ & $3(2-4)$ & -2.5 & $0.01^{*}$ \\
\hline Sleep efficiency & $66.5(33.7-80)$ & $65.4(17.5-79)$ & -0.2 & 0.81 \\
\hline $\mathrm{AHI}$ & $16.1(3-65.2)$ & $26.8(4-106.8)$ & -2.1 & $0.04^{*}$ \\
\hline $\mathrm{RDI}$ & $16.2(5-65.2)$ & $26.8(7-106.8)$ & -2.3 & $0.022^{*}$ \\
\hline ODI & $15.8(0.5-84.9)$ & $44.4(1.1-116.1)$ & -2.9 & $0.003^{*}$ \\
\hline
\end{tabular}

MW Mann-Whitney, FEV1 forced expiratory volume in the 1st second, FVC forced vital capacity, SBQ STOP-Bang questionnaire, ESS Epworth Sleep Scale, mMRC modified medical research council, $A H I$ apnea hypopnea index, $R D /$ respiratory disturbance index, $O D /$ oxygen desaturation index

*Significant

**Highly significant 
Table 3 OSA prevalence in COPD

\begin{tabular}{|c|c|c|c|c|c|c|c|c|c|c|}
\hline & \multicolumn{6}{|c|}{ COPD severity } & \multirow{2}{*}{\multicolumn{2}{|c|}{ Total $(N=100)$}} & \multirow[t]{3}{*}{$x^{2}$} & \multirow[t]{3}{*}{$\mathbf{P}$} \\
\hline & \multicolumn{2}{|c|}{ Mild $(N=22)$} & \multicolumn{2}{|c|}{ Moderate $(N=53)$} & \multicolumn{2}{|c|}{ Severe $(N=25)$} & & & & \\
\hline & $N$ & $\%$ & $N$ & $\%$ & $N$ & $\%$ & $N$ & $\%$ & & \\
\hline OSA & 7 & $31.8 \%$ & 22 & $41.5 \%$ & 21 & $84 \%$ & 50 & $50 \%$ & 20.5 & $<0.001^{* *}$ \\
\hline
\end{tabular}

COPD chronic obstructive pulmonary diseases, OSA obstructive sleep apnea

**Highly significant

Table 4 Prevalence of OSA among obese and non-obese COPD patients

\begin{tabular}{|c|c|c|c|c|c|c|c|c|c|c|c|c|c|c|c|c|}
\hline & \multicolumn{16}{|c|}{ COPD severity } \\
\hline & \multicolumn{6}{|c|}{ Non-obese } & \multirow{3}{*}{ Total $(N=50)$} & \multirow[t]{3}{*}{$P$} & \multicolumn{6}{|c|}{ Obese } & \multirow{3}{*}{ Total $(N=50)$} & \multirow[t]{3}{*}{$P$} \\
\hline & \multicolumn{2}{|c|}{$\begin{array}{l}\text { Mild } \\
(N=20)\end{array}$} & \multicolumn{2}{|c|}{$\begin{array}{l}\text { Moderate } \\
(N=26)\end{array}$} & \multicolumn{2}{|c|}{$\begin{array}{l}\text { Severe } \\
(N=4)\end{array}$} & & & \multicolumn{2}{|c|}{$\begin{array}{l}\text { Mild } \\
(N=2)\end{array}$} & \multicolumn{2}{|c|}{$\begin{array}{l}\text { Moderate } \\
(N=27)\end{array}$} & \multicolumn{2}{|c|}{ Severe $(N=21)$} & & \\
\hline & $\mathrm{N}$ & $\%$ & $\mathrm{~N}$ & $\%$ & $\mathrm{~N}$ & $\%$ & & & $\mathrm{~N}$ & $\%$ & $\mathrm{~N}$ & $\%$ & $\mathrm{~N}$ & $\%$ & & \\
\hline OSA & 6 & $30 \%$ & 6 & $23.1 \%$ & 2 & $50 \%$ & $28 \%$ & $0.009^{*}$ & 1 & $50 \%$ & 16 & $59.3 \%$ & 19 & $90.5 \%$ & $72 \%$ & $0.009^{*}$ \\
\hline
\end{tabular}

COPD chronic obstructive pulmonary diseases, OSA obstructive sleep apnea

*Significant

significantly higher SBQ, ESS, mMRC questionnaires, AHI, RDI \& ODI. But, no difference was found in sleep efficiency between obese and non-obese OSA patients (Table 5). Both obese and non-obese COPD patients showed significant positive correlations between AHI and smoking index (SI), SBQ, ESS, mMRC, ODI, and NC, while AHI correlated negatively with FEV1. Only obeseCOPD patients showed a significant positive correlation with BMI (Table 6). Average oxygen saturation correlated negatively with both $\mathrm{NC}$ and $\mathrm{BMI}$ in all COPD patients (Table 7). Multivariate logistic regression analysis disclosed that BMI, FEV1, SI, and ODI were independent predictors of OSA in COPD patients (Table 8).

Table 5 Comparison of Questionnaires data and polysomnographic parameter between both OSA groups

\begin{tabular}{lllll}
\hline Parameter & \multicolumn{2}{l}{ Groups (OSA) } & Test & $\mathbf{P}$ \\
\cline { 2 - 3 } & Non-obese & Obese & & \\
& Median (range) & Median (range) & & \\
\hline SBQ & $3(2-5)$ & $4(3-7)$ & 2.8 & $0.005^{*}$ \\
ESS & $18(11-24)$ & $22(11-24)$ & 2.7 & $0.007^{*}$ \\
mMRC & $2(2-3)$ & $3(2-4)$ & 2.5 & $0.01^{*}$ \\
Sleep efficiency & $69.4(27-79)$ & $67.2(14.2-77)$ & -0.63 & 0.52 \\
AHI index & $18.2(6-72)$ & $30.9(7.6-106.8)$ & 2.01 & $0.04^{*}$ \\
RDI & $18.2(6-72)$ & $33.2(10-106.8)$ & 2.2 & $0.03^{*}$ \\
ODI & $15.8(10-84.9)$ & $48.5(11-116.1)$ & 2.7 & $0.007^{*}$ \\
\hline
\end{tabular}

SBQ STOP-Bang questionnaire, ESS Epworth Sleep Scale, $m M R C$ modified medical research council, $A H I$ apnea hypopnea index, $B M I$ body mass index, $R D I$ respiratory disturbance index, $O D I$ oxygen desaturation index

*Significant

\section{Discussion}

Sleep disturbances might occur in up to $75 \%$ of individuals with COPD and may be due to nocturnal respiratory symptoms particularly cough, sleep-disordered breathing mainly OSA, or combinations of these processes. The simultaneousness of COPD and OSA is known as the overlap syndrome and, although its prevalence is not greater than would be anticipated from the prevalence of either disorder alone, the overlap syndrome is associated

Table 6 Correlations between AHI index and certain studied parameters within each group

\begin{tabular}{|c|c|c|c|c|}
\hline \multirow[t]{3}{*}{ Parameters } & \multicolumn{4}{|c|}{ AHI index } \\
\hline & \multicolumn{2}{|c|}{ Non-obese } & \multicolumn{2}{|l|}{ Obese } \\
\hline & $r$ & $P$ & $r$ & $P$ \\
\hline Age & 0.16 & 0.45 & -0.07 & 0.6 \\
\hline BMl & 0.19 & 0.368 & 0.5 & $<0.001^{* *}$ \\
\hline FEV1 & -0.71 & $<0.001^{* *}$ & -0.73 & $<0.001^{* *}$ \\
\hline $\mathrm{SI}$ & 0.66 & $<0.001^{* *}$ & 0.75 & $<0.001^{* *}$ \\
\hline SBQ & 0.44 & $0.03^{*}$ & 0.51 & $<0.001^{* *}$ \\
\hline ESS & 0.75 & $<0.001^{* *}$ & 0.73 & $<0.001^{* *}$ \\
\hline $\mathrm{mMRC}$ & 0.5 & $0.011^{*}$ & 0.57 & $<0.001^{* *}$ \\
\hline ODI & 0.69 & $<0.001^{* *}$ & 0.86 & $<0.001^{* *}$ \\
\hline NC & 0.54 & $0.006^{*}$ & 0.34 & $0.003^{*}$ \\
\hline
\end{tabular}

$r$ correlation coefficient, $A H I$ apnea hypopnea index, BMI body mass index, FEV1 forced expiratory volume in the 1st second, SI smoking index, SBQ STOP-Bang

Questionnaire, ESS Epworth Sleep Scale, $m M R C$ modified medical research council, $O D /$ oxygen desaturation index, NC neck circumference

*Significant

**Highly significant 
Table 7 Correlation of average oxygen saturation with BMI and neck circumference in COPD patients

\begin{tabular}{lll}
\hline & \multicolumn{2}{c}{ Average oxygen saturation } \\
\cline { 2 - 3 } & $\boldsymbol{R}$ & $\boldsymbol{p}$ value \\
\hline NC & -0.27 & $0.007^{*}$ \\
BMI & -0.23 & $0.02^{*}$ \\
\hline
\end{tabular}

$N C$ neck circumference, $B M I$ body mass index

*Significant

with significant nocturnal hypoxemia and impaired sleep quality [15].

The estimated prevalence of sleep disturbance in COPD varies from 34 to $78 \%$ [16]. COPD and OSA are frequent in the general population and give out a huge danger of expanded morbidity and mortality when they exist together in a similar patient. Clinicians should cautiously assess the clinical results and the high danger of cardiovascular problems connected to the overlap [17]. In the current work, studied groups were matched regarding age and sex distribution (most of the participants were males) while BMI and NC were higher in obese COPD patients. Compared to women, men have a higher rate of being obese or overweight. Also, fat deposits in the upper respiratory tract and hormonal changes related to obesity (increase leptin and insulin) predispose to OSA [18].

Qinhan et al. demonstrated in a similar study on 116 COPD patients that OS was frequent in obese men characterized by higher BMI $\left(38 \mathrm{~kg} / \mathrm{m}^{2}\right), \mathrm{NC}(38.8 \mathrm{~cm})$, and SI (800 pack/year) [19]. In a comparative study, Soler and his colleagues found that most of the participants were elderly male, and subjects with OS had significant increases in BMI, NC, and greater smoking history with more prevalent OSA among overweight subjects (75\%)
[20]. Similarly, Gunduz et al. concluded that overweight COPD patients with BMI $>27 \mathrm{~kg} / \mathrm{m}^{2}$ had a higher possibility of developing OSA [21].

In the current study, the obese-COPD group had the worst spirometric parameter and higher sleep and dyspnea questionnaire score with statistically significant differences compared to non-obese COPD patients. The progressive impairment of pulmonary function noticed in COPD con increase the exertional dyspnea which in turn limits the activities of daily living. Also, the presence of both COPD and obesity contribute to the presence of dyspnea, fatigue, and tiredness [22]. Watson et al. went in line with this finding as they detected that the annual decline in $\mathrm{FEV}_{1}$ in obese-COPD males was higher than in those with normal BMI. Furthermore, excessive weight gain had been linked to a decline in lung function, especially FVC. In general, obesity is connected with diminished $\mathrm{FEV}_{1}$ and weight acquire has been shown to decrease pulmonary function longitudinally. Nevertheless, BMI as an adiposity marker cannot separate between body fat and muscle tissue which may influence lung function [23]. Also, non-obese COPD patients without OSA had higher FEV1/FVC and FEV1 compared to obese patients [19]. Similarly, Zhu et al. in their study reported that the FVC and $\mathrm{FEV}_{1}$ in obese patients with OS were significantly diminished than in non-obese COPD patients $(P<0.01)$ [24]. On the other hand, Sleep quality and quality of life were impaired in patients with moderate to very severe COPD. Also, Pittsburgh Sleep Quality Index (PSQI), ESS, mMRC dyspnea scale, and short-form 36 health survey questionnaires (SF-36) were higher especially in obese patients with OSA [25]. In another comparable study, Berlin and modified Berlin scales were higher in OS than COPD patients [19].

Table 8 Multiple regression analysis of age BMI, post FEV1, smoking index, baseline $\mathrm{O}_{2} \%$ and neck circumference as an independent variable for $\mathrm{AHI}$

\begin{tabular}{|c|c|c|c|c|c|c|c|}
\hline & \multicolumn{2}{|c|}{ Unstandardized coefficients } & \multirow{2}{*}{$\begin{array}{l}\text { Standardized } \\
\text { coefficients } \\
\beta\end{array}$} & \multirow[t]{2}{*}{$\mathbf{t}$} & \multirow[t]{2}{*}{ Sig. } & \multicolumn{2}{|c|}{$95.0 \%$ confidence interval for $\beta$} \\
\hline & $B$ & SE & & & & Lower bound & Upper bound \\
\hline BMI & -0.44 & 0.19 & -0.15 & -2.38 & 0.02 & -0.81 & -0.07 \\
\hline FEV1 & -0.55 & 0.22 & -0.33 & -2.48 & 0.02 & -0.99 & -0.11 \\
\hline $\mathrm{SI}$ & 0.2 & 0.09 & 0.26 & 2.13 & 0.04 & 0.013 & 0.38 \\
\hline ODI & -2.34 & 0.47 & -0.36 & -4.99 & $<0.001$ & -3.28 & -1.41 \\
\hline NC & 1.75 & 0.92 & 0.12 & 1.89 & 0.06 & -0.09 & 3.58 \\
\hline PHT & 0.16 & 0.20 & 0.049 & 0.78 & 0.44 & -0.25 & 0.56 \\
\hline (Constant) & 224.75 & & & & & & \\
\hline
\end{tabular}

$\beta$ regression coefficient, $S E$ standard error $p<0.05$ is significant

Dependent variable: $\mathrm{AHI}$ index, $A H I$ apnea hypopnea index, BMI body mass index, FEV1 forced expiratory volume in the 1 st second, $S /$ smoking index, ODI oxygen desaturation index, NC neck circumference, $P H T$ pulmonary hypertension 
In this study, there was a statistically significant difference between the studied groups (obese and non-obese COPD, obese and non-obese OSA) regarding AHI, RDI \& ODI as they were significantly higher in obese COPD and COPD-OSA patients. However, there was no statistically significant dissimilarity as regard sleep efficiency.

This can be explained by the presence of well-known factors that exaggerate oxygen desaturation in obese patients as low baseline oxygen saturation, low lung volume, and high oxygen expenditure which could be exaggerated by diurnal and nocturnal hypoxemia of COPD [26].

Turcani et al. went in line with this result as they found that patients with ODI over $15 / \mathrm{h}$ had an elevated weight, BMI, and NC [27]. In a study done by Marin et al., ODI, RDI, and AHI were higher in the overlap syndrome in comparison to COPD patients without OSA [28]. Also, Anisa et al. demonstrated that severe COPD patients had a chance of 4.39 times to experience OSA than mild to moderate COPD [29].

In this work, OSA increases with increasing COPD severity (either obese or non-obese) with a total prevalence of $50 \%$. OSA prevalence in non-obese COPD was $28 \%$ and in obese patients was $72 \%$. This could be explained by the presence of common risk factors that lead to OSA and COPD including high BMI and smoking also utilization of inhaled corticosteroids in more advanced COPD may contribute to OSA by causing upper airway myopathy or extrapulmonary inflammation, which may impair upper airway reflexes or neuromuscular responses [30]. Patil et al. found that from 30 COPD patients, 23 of them had OSA. Four patients (17.33\%) were within ordinary BMI and 19 (82.6\%) were overweight [31]. While Wan et al. found a prevalence of OSA of $52.8 \%$ in patients with COPD [32], others reported a prevalence of $63.9 \%$ and $65.9 \%$ in moderate to severe COPD [20, 33]. Gunduz et al. found that the frequency of OS in mild hypoxemic COPD patients without symptoms of sleep apnea reached 58\% [21]. On the other hand, Zhu et al. reported that $67.9 \%$ of COPD patients enrolled in their study had OS with wide range of OSA prevalence in different degrees of COPD extending from 2.9 to $65.9 \%$ [24]. Similarly, Narasimhan and his colleagues found that the prevalence of OSA in COPD was $53 \%$ [34].

In the current study, there were significant positive correlations between $\mathrm{AHI}$ and SI, SBQ, ESS, mMRC dyspnea scale, ODI, and $\mathrm{NC}$ in both obese and non-obese COPD patients while AHI correlated negatively with FEV1 in both groups. COPD patients usually are smokers or ex-smokers. Smoking can lead to inflammation of the upper airway which in turn leads to swelling, narrowing, and probably closure of the airway. OSA was reported to be approximately three times more prevalent in ever-smokers than never-smokers [35]. Mengqing et al. found that an SBQ score of $\geq 3$ is able to determine OSA in COPD patients and a score of $\geq 4$ can recognize a high chance for developing severe OSA and they concluded that it correlates well with the degree of disease severity [36]. Similarly, in a study done by Narasimhan et al. on 66 COPD patients, they found a significant correlation between AHI and ESS, mMRC, and FEV1. So, poor lung function (reflected by FEV1) was connected to higher grade of OSA [34]. However, Jaoude and El-solh did not find a significant relation between the severity of airflow limitation and AHI [37]. Turcani et al. found a statistically significant relation between categorized $\mathrm{AHI}$ and weight, $\mathrm{BMI}, \mathrm{NC}$, and ESS. It is obvious that with increasing weight, BMI, NC and ESS, AHI, and OSA severity increased. And they concluded that as long as the AHI increased, the oxygen saturation decreased [27].

In this study, a significant negative correlation was found between average oxygen saturation and both $\mathrm{NC}$ and BMI in all COPD patients. This could be explained by the combined effect of obesity in reducing the functional residual capacity (FRC) and increasing the closing volume that leads to a greater tendency for small airway closure, causing ventilation-perfusion mismatching and pulmonary shunting, thus exacerbating oxygen desaturation [38]. Peppard et al. agreed with this as they found that BMI is the main factor to anticipate the intensity of oxygen desaturation during apnea or hypopnea [39].

In the current work, multivariate logistic regression analysis disclosed that BMI, Post FEV1, SI, and ODI were independent predictors of OSA in COPD patients with no effect of pulmonary hypertension on OSA in COPD patients. The presence of $\mathrm{PH}$ was mostly related to BMI, nocturnal hypoxia, and COPD itself but AHI was not an independent risk factor for $\mathrm{PH}$. So, it is difficult to find out if $\mathrm{PH}$ is due to intermittent hypoxemia produced by sleep apnea or persistent hypoxemia related to chronic lung disease. Sreedharan et al. in a similar study found that ODI is an independent predictor of OSA and they found a positive correlation between OSA severity and nocturnal hypoxemia [40]. The median pulmonary artery pressure (PAP) was found to be similar in COPD patients irrespective to OSA presence. Also, AHI did not correlate with PAP in a similar study [41]. Izabella and his colleagues agreed with this finding as they found that BMI, NC, head circumference (HC), ESS, and smoking index were independent variables for OSA [42]. Another study demonstrated that common OSA predictors (e.g., gender, ESS) did not perform well in patients with more advanced COPD [43]. In the study done by Sharma et al. on 206 COPD patients, they demonstrated that $\mathrm{BMI}$, male gender, 
informed snoring index, and choking index were independent predictors of OSA in COPD patients. They suggested that the chance of developing OSA increases with increasing BMI [44]. It is well known that patients with COPD and OSA are more vulnerable to pulmonary hypertension, which is associated with a reduction in lung function and increased OSA severity. So, hypoxemia and OSA in elderly COPD patients should be recognized and managed properly [41].

\section{Conclusion}

From this study, it can be concluded that moderate and severe COPD patients had a higher diagnosis of sleepdisordered breathing. Also, obese-COPD patients are more susceptible to develop OSA.

\begin{abstract}
Abbreviations
COPD: Chronic obstructive pulmonary disease; OSA: Obstructive sleep apnea; OS: Overlap syndrome; BMI: Body mass index; FEV1: Forced expiratory volume in the 1st second; FVC: Forced vital capacity; ENT: Ears, nose, and throat; NC: Neck circumference; ESS: Epworth Sleepiness Scale; SBQ: STOP-Bang Questionnair; mMRC: Modified medical research council; T3: Triiodothyronine; T4: Thyroxine; TSH: Thyroid-stimulating hormone; PSG: Polysomnography; EEG: Electroencephalogram; EOG: Electrooculogram; ECG: Electrocardiogram; EMG: Electromyogram; AHI: Apnea-hypopnea index; RDI: Respiratory disturbance index; ODI: Oxygen desaturation index; SI: Smoking index; PSQI: Pittsburgh Sleep Quality Index; SF-36: Short-form 36 health survey questionnaires; FRC: Functional residual capacity; PAP: Pulmonary artery pressure; 6MWT: Six-minute walk test; $\mathrm{PaO} 2$ : Arterial oxygen tension; $\mathrm{PaCO} 2$ : Carbon dioxide oxygen tension; HC: head circumference.
\end{abstract}

\section{Acknowledgements}

None.

\section{Authors' contributions}

AE made a substantial subscription to the conception and plan of the work, OM contributed to acquiring, evaluation, and explanation of evidence. SM contributed to the design of new software utilized in this work. ME outlined the work and rescripted it. All authors read and authorized the final manuscript.

\section{Funding}

None.

\section{Availability of data and materials}

Not applicable.

\section{Declarations}

\section{Ethics approval and consent to participate}

The research ethics committee at the Faculty of Medicine, Benha University (no. 63), has approved the study (12/6/2018) and all patients provided a written consent before participation.

\section{Consent for publication}

Not applicable.

\section{Competing interests}

The authors declare that they have no competing interests.

Received: 14 April 2021 Accepted: 18 September 2021

Published online: 19 October 2021

\section{References}

1. Global Initiative for Chronic Obstructive Lung Disease (GOLD 2020); Global strategy for the diagnosis, management and prevention of COPD.NHLB/WHO global initiative for chronic obstructive pulmonary disease.http://goldcopd.org/gold-reports/. Accessed on 12 Dec.2020

2. Stöwhas AC, Lichtblau M, Bloch KE (2019) Obstructive Sleep Apnea Syndrome. Praxis (Bern 1994) 108(2):111-117

3. Flenley DC (1985) Sleep in chronic obstructive lung disease. Clin Chest Med 6:651-661

4. Mathers CD, Loncar D (2006) Projection of global mortality and burden of disease from 2002 to 2003. PLoS Med 3:442

5. Sanders $M H$, Newman AB, Haggerty $C L$ et al (2003) Sleep and sleep disordered breathing in adults with predominantly mild obstructive airway disease. Am J Respir Crit Care Med 167:7-14

6. McNicholas WT (2016) Chronic obstructive pulmonary disease and obstructive sleep apnoea - the overlap syndrome. J Thorac dis. 8(2):236-242)

7. Lavie P, Herer P, Lavie L (2007) Mortality risk factors in sleep apnoea: a matched case-control study. J Sleep Res 16:128-134

8. Mokhlesi B (2010) Obesity hypoventilation syndrome: a state-of-the-art review. Respir Care 55:1347-1362

9. Global Initiative for Chronic Obstructive Lung Disease (GOLD 2017); Global Strategy for the Diagnosis, Management and prevention of COPD. NHLB/WHO Global initiative for chronic obstructive pulmonary disease

10. Anwar E, Abdulhamid F, AbdullahAl H, Abdullah A, Yosra Z, Salim B et al (2014) Validation of the Arabic version of the Epworth sleepiness scale. J Epidemiology Global Health 2014:297-302

11. Chung $F$, Yegneswaran B, Liao P, Chung SA, Vairavanathan $S$, Islam $S$ et al (2008) (2008). STOP questionnaire: a tool to screen patients for obstructive sleep apnea. Anesthesiology. 108:812-821

12. Alyami M, Jenkins S, Lababidi H, Hill K (2015) Reliability and validity of an Arabic version of dyspnea -12 questionnaire for Saudi nationals with chronic obstructive pulmonary disease. Ann Thoracic Med 10(2):112-117

13. (Memon J, Manganaro SN. Obstructive Sleep-disordered Breathing. [Updated 2020 Aug 14]. In: StatPearls [Internet]. Treasure Island (FL): StatPearls Publishing; 2021 Jan-. Available from: https://www.ncbi.nlm. nih.gov/books/NBK441909/)

14. Kothari CR (2004). Research methodology: methods and techniques.2nd ed. New Delhi: new age international publishers; 2004

15. Kumar A, Gautam AK, Gautam V, Gupta AK, Yadav P, Singh NP et al (2020) Prevalence of obstructive sleep apnoea in chronic obstructive pulmonary disease patients. IJMSCR 3:370-377

16. Sleep Quality in COPD. [Last accessed on 31 May 2019]. Available from:http://www.thoracic.org/copd-guidelines/for-health professionals/ management-of-stable-copd/sleep/sleep-problems-in-copd.php

17. Gharib A (2020) The deleterious effects of chronic obstructive pulmonary disease and obstructive sleep apnea: pathophysiology and implications on treatment. Egypt J Bronchol 14:24. https://doi.org/10.1186/ s43168-020-00026-X

18. Jehan S, Zizi F, Pandi-Perumal SR, Wall S, Auguste E, Myers AK, Jean-Louis G, McFarlane SI (2017) Obstructive sleep apnea and obesity: implications for public health. Sleep Med Disord 1(4):00019

19. Qinhan W, Liang X, Wenjing L, Guiling X, Weiping H, Hong J, et aL. Pulmonary function influences the performance of Berlin questionnaire, modified Berlin questionnaire, and STOP-bang score for screening obstructive sleep apnea in subjects with chronic obstructive pulmonary disease. Int J Chron Obstruct Pulmon Dis, 2020;15:1207-1216

20. Soler X, Gaio Eo, Frank L P, Joe W R, Jose S L, Atul M et al. High Prevalence of Obstructive Sleep Apnea in Patients with Moderate to Severe COPD. Annals ATS. 14-April-2015. as 10.1513/ 201407-3360C

21. Gunduz C, Basoglu OK, Tasbakan MS (2018) Prevalence of overlap syndrome in chronic obstructive pulmonary disease patients without sleep apnea symptoms. Clin Respir J 12(1):105-112. https://doi.org/10.1111/crj. 12493

22. Pissulin FDM, Pacagnelli FL, Aldá MA, Beneti R, Barros JL, Minamoto ST, Weber SAT (2018) The triad of obstructive sleep apnea syndrome, COPD, and obesity: sensitivity of sleep scales and respiratory questionnaires. J Bras Pneumol 44(3):202-206

23. Watson L, Vonk JM, Lofdahl CG, Schouten JP, Postma DS, Pride NB et al (2006) Predictors of lung function and its decline in mild to moderate 
COPD in association with gender: results from the Euroscop study. Respir Med 100:746-753

24. Zhu J, Zhao Z, Nie Q, Wang Y, Fu Z, Guo X et al (2020) Effect of lung function on the apnea-hypopnea index in patients with overlap syndrome: a multicenter cross-sectional study. Sleep Breath 24:1059-1066. https://doi. org/10.1007/s11325-019-01961-w

25. Buket A, Gökşen K, Esen K (2018) (2017). Sleep quality and quality of life in patients with moderate to very severe chronic obstructive pulmonary disease. Clin Respir J 12(4):1739-1746

26. Nakano H, Ikeda T, Hayashi M, Ohshima E, Itoh M, Nishikata N et al (2004) Effect of boby mass index on overnight oximetry for the diagnosis of sleep apnea. Respir Med 98:421-427

27. Turcania P, Skrickova J, Pavlik T, Janousova E, Orban M (2015) The prevalence of obstructive sleep apnea in patients hospitalized for COPD exacerbation. Biomed Pap Med Fac Univ Palacky Olomouc Czech Repub 159(3):422-428

28. Marin J, Soriano J, Carrizo S, Boldova A, Celli B (2010) Outcomes in patients with chronic obstructive pulmonary disease and obstructive sleep apnea: the overlap syndrome. Am J Respir Crit Care Med 182(3):325-331

29. Anisa I R, Siswantining T, Kamelia T and Sarwinda D. Risk Prediction Model Occurrence of Obstructive Sleep Apnea (OSA) Risk in Chronic Obstructive Pulmonary Disease patient. Case Study: Cipto Mangunkusumo Hospital. IOP Conf. Series: Journal of Physics: Conf. Series 1108 (2018) 012076 doi :https://doi.org/10.1088/1742-6596/1108/1/012076

30. Teodorescu M, Xie A, Sorkness CA, Robbins J, Reeder S, Gong Y et al (2014) Effects of inhaled fluticasone on upper airway during sleep and wakefulness in asthma: a pilot study. J Clin Sleep Medicine 10:183-193

31. Patil P, Jayalakshmi T, Abhay U, Girija N, Pragati A (2016) AHI and nocturnal desaturation in COPD patients: an early indicator for LTOT/CPAP therapy. International Journal of Current Research 8(06):33340-33344

32. Wan S, Jian W, Guo J, Wen M, Yi-Xuan L, Yong H (2019). Impact of obstructive sleep apnea on pulmonary hypertension in patients with chronic obstructive pulmonary disease. Chin med J (Engl). 2019;132(11):1272-82

33. Venkateswaran S, Tee A (2014) Overlap syndrome between chronic obstructive pulmonary disease and obstructive sleep apnoea in a southeast Asian teaching hospital. Singap Med J 55:488-492

34. Narasimhan M, Sharma R, Shanmuganathan A, Vallabhaneni V, Rajalingam R, Ganga N et al (2017) (2017). Correlation of severity of apnea hypopnea index (AHI) with forced expiratory volume 1(FEV1) in overlap syndrome. Journal of evidence based medicine and healthcare 4(69):4097-4104
35. McNicholas WT (2009) Chronic obstructive pulmonary disease and obstructive sleep apnea: overlaps in pathophysiology, systemic inflammation, and cardiovascular disease. Am J Respir Crit Care Med 180:692-700

36. Mengqing X, Weihua $H$, Minglin D, Meifang W, Junwen C, Hanzhong X et al (2019) The screening value of ESS, SACS, BQ, and SBQ on obstructive sleep apnea in patients with chronic obstructive pulmonary disease. Int J Chron Obstruct Pulmon Dis 14:2497-2505

37. Jaoude P, El-solh AA. Predictive factors for COPD exacerbation and mortality in patients with overlap syndrome. The clinical respiratory journal.2019;13:643-51

38. Lehrman SG, Limann B, Koshy A, Aronow WS, Ahn C, Maguire G (2008) Association of lung volumes with nocturnal oxygen saturation in obese persons: a possible role for therapeutic continuous positive airway pressure. Am J Ther 15(3):221-224

39. Peppard PE, Ward NR, Morrell MJ (2009) The impact of obesity on oxygen desaturation during sleep disordered breathing. Am J Respir Crit Care Med 180(8):778-793

40. Sreedharan S, Agrawal P, Rajith R, Nair S, Sarma S, Radhakrishnan A (2016) Clinical and polysomnographic predictors of severe obstructive sleep apnea in the south indian population. Ann indian Acad Neuroi 19(2):216-220

41. Sun WL, Wang JL, Jia GH, Mi WJ, Liao YX, Huang YW, et al. Impact of obstructive sleep apnea on pulmonary hypertension in patients with chronic obstructive pulmonary disease. chin Med J (Engl). 2019;132(11):1272-82

42. Izabella A, Sorin P, Stefan M (2014) Independent predictors for sleep apnea syndrome in a clinical prediction model. Chest Sleep disorders 145(3):587A

43. Soler X, Liao S Y, Marin J M, Lorenzi-Filho G, Jen R, DeYoung P et al. Age, gender, neck circumference, and Epworth sleepiness scale do not predict obstructive sleep apnea (OSA) in moderate to severe chronic oAbstructive pulmonary disease (COPD): The challenge to predict OSA in advanced COPD. PloS one.2017; 12(5): e0177289

44. Sharma SK, Malik V, Vasudev C, Banga A, Mohan A, Handa KK et al (2006) Prediction of obstructive sleep apnea in patients presenting to a tertiary care center. Sleep Breath 10(3):147-154

\section{Publisher's Note}

Springer Nature remains neutral with regard to jurisdictional claims in published maps and institutional affiliations.

\section{Submit your manuscript to a SpringerOpen ${ }^{\circ}$ journal and benefit from:}

- Convenient online submission

- Rigorous peer review

- Open access: articles freely available online

- High visibility within the field

Retaining the copyright to your article

Submit your next manuscript at $\boldsymbol{\nabla}$ springeropen.com 